\title{
Adquirindo durações vocálicas de L2, ou não? Sexo e background linguístico como fatores de investigação
}

\section{Acquiring L2 vocalic durations, or not? Sex and linguistic background as investigation factors}

\author{
Amanda Post da Silveira ${ }^{1}$ \\ Universidade Federal de São Carlos, Brasil
}

Recebido em: $15 / 05 / 2020$

Aceito em: 21/07/2020

\begin{abstract}
RESUMO
Os fenômenos da aquisição fonético-fonológicos específicos a homens e mulheres são, relativamente, pouco explorados. Os estudos fazem, frequentemente, médias com os dados de produção fonética de homens e mulheres, com o fim de neutralizar o efeito das diferenças de sexo. Este estudo pretende investigar a aquisição da duração vocálica do inglês americano como produzida por falantes mulheres e homens falantes nativos de português brasileiro. Os resultados mostraram que as mulheres produzem vogais mais longas do que os homens tanto no grupo controle monolíngue quanto no grupo experimental bilíngue. As análises estatísticas indicam que os efeitos relativos às diferenças entre sexo e os efeitos relativos à aquisição de L2 não estão correlacionados. Tais resultados são interessantes para argumentamos em favor de que estudos em aquisição de L2 e fonética devem sempre considerar as diferenças de aquisição e performance entre os sexos, a fim de que importantes fenômenos específicos ao sexo não sejam ignorados.
\end{abstract}

PALAVRAS-CHAVE:

Produção de fala. Duração vocálica. Aquisição de L2. Diferenças entre sexos.

\begin{abstract}
Phonetic-phonological acquisition phenomena specific to men and women are relatively little explored. Studies often average with data on the phonetic production of men and women, in order to neutralize the effect of gender differences. This study aims to investigate the acquisition of American English vowel duration as produced by women and men who are native speakers of Brazilian Portuguese. The results showed that women produce longer vowels than men both in the monolingual control group and in the bilingual experimental group. Statistical analyzes indicate that the effects related to the differences between sex and the effects related to the acquisition of $L 2$ are not correlated. Such results are interesting to argue in favor of that studies on L2 acquisition and phonetics should always consider the differences in acquisition and performance between the sexes, so that important sex-specific phenomena are not ignored.
\end{abstract}

KEYWORDS:

Speech production. Vowel duration. L2 acquisition. Sex-specific differences.

\footnotetext{
${ }^{1}$ E-mail: psyphon.ap@gmail.com | ORCID: 0000-0002-9451-7005.
} 


\section{Introdução}

É bem estabelecido na literatura de ciências fonéticas que homens e mulheres (que representaremos aqui com a variável sexo) apresentam diferenças morfológicas ou até mesmo características sociolinguísticas que os fazem produzir discursos diferentemente uns dos outros, conforme demonstrado, por exemplo em Simpson e Ericsdotter (2003) e Simpson (2003). O pitch médio é mais elevado nas mulheres do que nos homens (HAAN \& VAN HEUVEN, 1999), também os formantes das vogais têm frequências mais elevadas nas mulheres do que nos homens. Menos, contudo, tem sido dito na literatura sobre diferenças intersexuais na produção de duração da vogal.

Estudos têm mostrado recorrentemente que falantes femininos de alemão, sueco e inglês americano como L1 produzem vogais mais longas do que os falantes masculinos (SIMPSON, 1998, 2003; ERICSDOTTER \& ERICSSON, 2001). Esses estudos utilizaram dados provenientes de leitura de frases bem como de fala espontânea. Os resultados apoiam uma explicação biomecânica para a diferença entre homens e mulheres quanto às durações vocálicas. A explicação corrobora um alongamento temporal das vogais por mulheres a fim de compensar um intervalo vocal mais curto do que homens a fim de conseguir alvos fonéticos similares nos termos da produção vocálico. A diferença na duração é conseguida movendo suas línguas em velocidades diferentes, mulheres movem suas línguas mais lentamente do que homens. A evidência para a hipótese biomecânica vem dos estudos acima mencionados, que mostram similaridades interlinguísticas consistentes em seus resultados. Estes resultados têm implicações importantes para a dinâmica sexual na síntese e tipologia da fala (ERICSDOTTER \& ERICSSON, 2001), uma vez que identificam fenômenos de ordem biológica e social que são específicos a homens e mulheres.

Em ambos os estudos de Ericsdotter \& Ericsson (2001) e Simpson (1998) uma outra explicação possível é dada ao fato de que que não somente maiores durações vocálicas podem ser produzidas por mulheres, mas que também diferenças maiores da duração entre categorias em consequência dos fatores sociofonéticos relativos ao sexo feminino. Por exemplo, as mulheres produzem um discurso mais claro do que os homens, porque sua produção vocálica pode ser mais estável em relação a espectros e durações, o que inclui um maior contraste entre as durações de vogais longas e reduzidas.

Enquanto existem alguns trabalhos que exploram o fenômeno da duração vocálica diferenciadamente produzida por falantes nativos das línguas supracitadas, poucos estudos antes 
de Post da Silveira e Varkevisser (2019) haviam analisado estatisticamente as diferenças vocálicas produzidas intersexo em fala bilíngue comparativamente à monolíngue.

O objetivo deste estudo foi o de discutir os dados de Post da Silveira e Varkevisser (2019) e um apanhado de estudos de fala monolíngue argumentando a existência de um fenômeno separado para os sexos biológicos humanos quanto à produção de vogais longas e reduzidas, que é simétrico na fala de monolíngues e bilíngues consecutivos tardios, no processo de aquisição de L2 (Post da Silveira \& Varkevisser, 2019).

\subsection{Duração de vogais em homens e mulheres monolíngues}

Os estudos recentes de diversas línguas indo-europeias, e pelo menos uma língua nãoindo-europeia, relataram diferenças nos testes padrões segmentais masculinos e femininos quanto ao correlato acústico de duração, tais que as durações femininas são mais longas. Em um estudo do alemão aproximadamente 60.000 tokens de vogal do discurso lido e espontâneo de 25 mulheres e 29 homens falantes de alemão do Norte (SIMPSON, 1998), todas as durações femininas de vogal foram realizadas com maior duração. As diferenças proporcionais foram mantidas nos dois estilos de fala, apesar da esperada redução das durações médias para a fala espontânea.

Os falantes femininos do estudo de Simpson (2003) sobre vogais do inglês americano com 8 participantes (4 mulheres, 4 homens) também mostrou que mulheres produziram maiores diferenças duracionais entre as categorias de vogais longas e curtas. Em um estudo voltado especificamente para investigar padrões de duração específicos do sexo em Sueco (ERICSDOTTER \& ERICSSON, 2001), além de encontrar maiores durações de vogal, os falantes femininos também tiveram maiores diferenças de duração entre vogais tônicas e átonas. Uma possível explicação para maiores durações de vogais, bem como para maiores diferenças duracionais entre as categorias é sociofonética. Produzir durações mais longas e maiores diferenças duracionais pode ser visto como um dos correlatos de falar mais claramente, um atributo que foi atribuído ao discurso feminino (ELYAN, 1978). No entanto, semelhanças na dimensão e natureza das diferenças encontradas nas línguas citadas indicam que possíveis explicações morfológicas da biologia dos sexos devem ser exploradas. Simpson $(2001,2002)$ especula que durações femininas mais longas na produção de sequência de ditongos e vogais podem ser uma consequência temporal de diferenças específicas do sexo em distâncias articulatórias que devem ser atravessadas para 
atingir alvos fonéticos análogos.

\subsection{Durações de vogais no português brasileiro produzidas por homens e mulheres}

No estudo de Rauber (2006), mede vogais que foram produzidas por brasileiros monolíngues em não palavras formadas pela sequência CVCV dissilábica $(C=$ consoante, $V=$ vogal), onde as duas consoantes eram duas oclusivas ou fricativas desvozeadas em palavras tais como / pepo / e / saso / (pêpo e sasso). Somente as vogais da primeira sílaba foram medidas. No que diz respeito às produções de mulheres e homens, o estudo não encontrou diferenças estatisticamente significantes entre os valores de durações vocálicas.

Contudo, em um estudo de Escudero et al. (2009), os dados quanto a duração vocálica produzida por homens e mulheres diverge dos resultados encontrados em Rauber (2006). No estudo de Escudero et al. (2009) tanto as vogais do português brasileiro quanto as do português europeu são investigadas. Neste estudo, foram medidas 5600 vogais possíveis no português brasileiro (/i, e, E, a, O, o, u/) que foram produzidas em não-palavras. Seguindo a mesma metodologia de Rauber (2006), tais não-palavras foram formadas em sequência CVCV dissilábica ( $C=$ consoante, $V=$ vogal), onde as duas consoantes eram duas oclusivas ou fricativas desvozeadas em palavras tais como / pepo / e / saso / (pêpo e sasso). Somente as vogais da primeira sílaba foram medidas. Os achados deste estudo vão ao encontro do que já havia sido encontrado para a duração vocálica de homens e mulheres em outras línguas por falantes monolíngues (e.g. Simpson, 1998; Ericsdotter \& Ericsson, 2001; Simpson, 2003), uma vez que foi encontrado que mulheres produzem vogais mais longas do que homens nas duas variantes do português.

\subsection{Duração da vogal e aquisição de L2}

Concomitantemente ao espectro da vogal, a duração da vogal é uma característica importante na relação dos fonemas vocais e do estresse das palavras em inglês. Portanto, medimos as durações da vogal para palavras em nosso conjunto de dados. No português do Brasil, apenas vogais espectrais plenas são encontradas tanto em posições de sílabas acentuadas quanto de sílabas não acentuadas, no sentido de que mesmo quando ocorre redução espectral, esta não é extrema o suficiente para tirá-las de sua categoria espectral vocálica, em outras palavras, vogais reduzidas não são fonêmicas na língua (NOBRE \& INGEMANN, 1986). Quando dizemos que o PB 
não reduz os espectros de vogais em uma posição átona, queremos dizer, por exemplo que, diferentemente da língua inglesa, não há vogais Schwas e Meio-Alta Meio-Frontal / I / no inventário dos falantes de BP como L1 (NOBRE \& INGEMANN 1986). Ressaltamos também que as diferenças duracionais entre vogais acentuadas e não acentuadas não são grandes no PB (MAJOR, 1985), mas a diferença existente entre vogais plenas e reduzidas da língua são suficientes para que os falantes nativos as usem como correlato na distinção entre uma sílaba acentuada de uma não acentuada.

Em contrapartida, em inglês, reduções temporais e espectrais de vogais funcionam como pistas acústicas de acento de palavras (CUTLER, 1986). Isso ocorre tal que, as vogais em sílabas acentuadas são realizadas como vogais plenas, enquanto as vogais que ocorrem em sílabas não acentuadas são quase sempre reduzidas a uma vogal Schwa ou Média-Alta Médio-Frontal (por exemplo, Liberman \& Prince, 1977). Acompanhando a redução espectral das vogais do inglês, há também a redução de duração vocálica, visto que as vogais plenas em sílabas acentuadas têm longa duração (por exemplo, PETERSON \& LAHISTE, 1960), enquanto vogais reduzidas em sílabas átonas são de curta duração. Assim, diferentemente do PB, a diferença duracional entre vogais plenas e reduzidas no inglês é grande.

1.4 Vogais reduzidas /I/ e schwa do inglês não-nativo produzidas por falantes nativos de português brasileiro

Com base na literatura sobre percepção e produção de segmentos ingleses por falantes nativos de português do Brasil (BAPTISTA, 2006; BION et al., 2006; RAUBER, 2006; NOBREOLIVEIRA, 2007), as duas vogais / I / e / i / não constituem categorias diferentes no sistema de tal grupo de falantes no que concerne valores de formantes F1 e F2. Como consequência, as palavras em inglês hit e heat podem parecer homófonas para esses falantes bilíngues.

Enquanto a maior parte dos trabalhos supracitados faz somente medições dos formantes F1 e F2 para demostrar a diferença em percepção e produção de / / / e / i / de falantes nativos de inglês e de bilíngues tardios português brasileiro (L1) - inglês (L2), o trabalho de Rauber (2006) há a indicação que a diferença de que a duração vocálica produzida para os dois fonemas pelo grupo bilíngue de mulheres e homens é insignificante, o que, porém, não foi demonstrado estatisticamente.

Quanto à produção da vogal média central Schwa, o estudo de Marusso e Cristófaro-Silva (2007) indica que um grupo de quatro falantes de inglês britânico e outro grupo de quatro falantes 
de inglês como L2, falantes nativos de português brasileiro, produzem formantes F1 e F2 e médias de duração vocálica comparativamente semelhantes. O trabalho de Bion et al. (2006), contudo, demonstra que a vogal schwa é produzida como uma vogal plena quanto a produção dos seus formantes F1 e F2 por falantes bilíngues tardios português brasileiro (L1) - inglês (L2).

A partir dos trabalhos encontrados sobre produção vocálica de schwa por bilíngues português inglês, parece fazer-se necessários estudos que abordem produção de durações vocálicas e que façam a comparação entre sexos dos bilíngues tardios do português brasileiro (L1) - inglês (L2). Este estudo pretende trazer uma contribuição nesta direção.

\subsection{Perguntas de Pesquisa de Hipóteses}

Tendo em vista as características da produção de durações vocálicas por homens e mulheres e por falantes nativos de inglês e falantes nativos de português, este estudo pretende responder às seguintes perguntas:

- Tal como falantes monolíngues, as mulheres bilíngues produzirão vogais mais longas do que os homens bilíngues?

- Visto que em fala bilíngue a produção de categorias da língua alvo pode ter uma representação e processamento mistos entre L1 e L2 (Post da Silveira, 2016), os falantes de inglês como L2 produzirão vogais mais longas do que os falantes monolíngues da língua?

- Os fatores sexo e bilinguismo são interdependentes, ou seja, o comportamento apresentado quanto à duração vocálica deve-se ao fato de ser homem ou mulher adquirindo uma L2?

Portanto, hipotetizamos que, tendo um sistema misto em que as representações da L1 são dominantes (Post da Silveira, 2016), os falantes de inglês como L2, mostrarão uma razão de duração menor entre vogais plenas e vogais reduzidas do inglês do que a do inglês monolíngue. Hipotetizamos, também, que mulheres bilíngues seguirão o mesmo padrão quanto à duração vocálica por mulheres monolíngues e produzirão vogais mais longas do que os homens bilíngues em inglês como língua alvo.

\section{Método}

\subsection{Participantes}


Para este estudo, 20 sujeitos participaram do experimento. Eles eram estudantes de intercâmbio em Leiden University Centre for Linguistics (LUCL), Leiden, Holanda. O grupo monolíngue inglês americano consistiu em 10 falantes monolíngues nativos do inglês americano (5 homens e 5 mulheres, faixa etária entre 19 e 48, idade média: 25,6 anos). 0 grupo de falantes não nativos de inglês americano consistiu em 10 participantes brasileiros com o português brasileiro como primeira língua e inglês como segunda língua (5 homens e 5 mulheres, idades variando entre 21 e 44 anos, média de idade: 30). Os falantes de L2 de inglês americano relataram suas pontuações em testes de proficiência em inglês, como testes de proficiência no TOEFL e IELTS. Como apenas três participantes realizaram o teste IELTS, transformamos suas pontuações em escores do TOEFL, usando as métricas fornecidas pela ferramenta de comparação do TOEFL. Após a transformação dos escores, foi possível selecionar os participantes que obtiveram pontuação igual a 90 ou acima, de acordo com os escores do TOEFL (média do TOEFL Scores =94,9, DP = 7,4). Os participantes não-nativos de inglês também realizaram o teste de vocabulário de inglês X_Lex 2.05 (MEARA \& MILTON, 2006). A fim de ser selecionado para o experimento, um participante devia marcar acima de 3.500 pontos no teste de vocabulário. Seus escores variaram entre 3.500 e 4.850 pontos $($ média $=4193$ pontos, DP $=418$ ) de um máximo de 5.000 pontos. O TOEFL e os escores X_Lex 2.05 avaliaram-nos como intermediários superiores a aprendizes avançados de inglês. Nenhum dos participantes relatou ter problemas auditivos e todos tinham visão normal ou corrigida para normal. A participação no experimento e os custos de viagem foram pagos. Alguns voluntários participaram sem compensação.

\subsection{Materiais de estímulo}

Utilizamos 360 palavras trissílabas, metade delas com a tônica na primeira sílaba e a outra metade com a tônica na segunda sílaba, como ADvocate e ADjective, com vogais plenas acentuadas na primeira sílaba (as letras maiúsculas indicam sílabas acentuadas), em oposição à gaLACtic e goRlla com vogais reduzidas não acentuadas na sílaba inicial (sublinhado indica sílaba não acentuada).

\subsection{Procedimento}

O experimento aconteceu no Laboratório de Fonética do Leiden University Centre for 
Linguistics. Os participantes foram posicionados em uma cabine de atenuação sonora e sentados a aproximadamente $60 \mathrm{~cm}$ de uma tela de computador (tamanho: 32,5 x $24 \mathrm{~cm}$ ). 0 experimento de nomeação de palavras foi implementado e apresentado com software E-Prime 2,0. As palavras inglesas foram apresentadas na fonte Arial preta com tamanho 18 pontos, no centro da tela. A lista de palavras de estímulo inglês foi randomizada para cada participante e dividida em quatro blocos experimentais contendo 90 palavras, cada uma contrabalançada no número de estímulos nos quais a primeira sílaba é tônica ou átona. As palavras-alvo foram precedidas por uma cruz de fixação (+) de 250 ms de duração e apresentadas individualmente por 1000 ms. Os participantes tiveram mais 3000 ms depois que a palavra desapareceu da tela para pronunciá-la antes que uma outra palavra aparecesse. Eles foram instruídos a ler a palavra na tela em voz alta o mais rápido e com a maior precisão possível. Um microfone de condensador unidirecional Sennheiser MKH-416 foi usado para captar a fala dos participantes diretamente em um PC (22.050 Hz, 16 bits/amostra) e o programa e-Prime 2.0 gravou e armazenou suas produções de fala para posterior análise. As sessões duraram 30 minutos em média. O experimento real foi precedido por uma fase de treinamento com a mesma dinâmica do experimento real, mas contendo 20 palavras de língua inglesa da variante americana que não foram incluídas na fase experimental.

\subsection{Transcrições fonéticas}

Um script do Praat (Boersma \& Weenink, 2001) foi usado para rastrear automaticamente as respostas de fala dentro da janela de tempo de resposta de 3 segundos. Os limites das palavras foram posteriormente corrigidos manualmente pela autora deste estudo. Um segundo script do Praat (Boersma \& Weenink, 2001) foi usado para rotular as palavras. Em seguida, um terceiro script Praat (Boersma \& Weenink, 2001) foi usado para alinhar e rotular automaticamente os segmentos de acordo com transcrições canônicas para cada palavra. O alinhamento e a rotulagem automáticos foram posteriormente verificados e corrigidos por dois peritos foneticista. As transcrições ambíguas foram descartadas pelos revisores e 9 palavras que resultaram em muitas ambiguidades na transcrição foram excluídas de nossas análises.

\section{Resultados}

Cada participante produziu 360 palavras, das quais 180 tinham acento na primeira sílaba e 
180 na segunda sílaba, fazendo um total de 7.200 tokens de palavras.

Somente as vogais na primeira e segunda sílabas dos tokens foram incluídas em nossas análises para evitar efeitos do alongamento da sílaba final. Assim, 14.040 vogais foram selecionadas, e após a exclusão dos outliers, foi utilizado um total de 11.459 vogais para a análise estatística.

A tabela 1 mostra os resultados para a duração de vogal por grupo linguístico, bem como a proporção de vogais com vogais longas acentuadas versus vogais reduzidas átonas produzidas na primeira e segunda sílabas de palavras trissilábicas em inglês.

Tabela 1 - Duração vocálica média por grupos de idiomas e sexo

\begin{tabular}{llccccc}
\hline & \multicolumn{2}{c}{ Vogais plenas } & \multicolumn{2}{c}{ Vogais reduzidas } & \multicolumn{2}{c}{ Fração plenas/reduzidas } \\
\hline & homens & mulheres & homens & mulheres & homens & mulheres \\
IA L1 & $102(34)$ & $116(43)$ & $59(28)$ & $71(36)$ & 1.73 & 1.63 \\
IA L2 & $107(39)$ & $116(39)$ & $74(36)$ & $82(40)$ & 1.45 & 1.41 \\
\hline
\end{tabular}

* Médias de duração vocálica em milissegundos

** Desvio padrão entre parênteses

A Tabela 1 indica que falantes nativos do inglês americano (IA L1) produziram uma maior diferença de duração entre vogais plenas e reduzidas em inglês do que os brasileiros (IA L2). A tendência de homens e mulheres do grupo IA L2 parece ser a de produzir uma diferença menor entre vogais plenas e reduzidas do que seus pares do grupo IA L1, o que é demonstrado pelos valores da fração.

Em relação às diferenças entre os sexos na duração das vogais, observou-se que as mulheres produziram vogais mais longas do que os homens tanto na categoria vogal completa quanto na categoria vogal reduzida. Embora o grupo IA L1 seja formado por participantes diferentes do grupo IA L2, observamos o mesmo padrão emergente na duração da vogal de homens e mulheres: as mulheres produzem vogais mais longas do que os homens tanto na sua L1 quanto na L2. As médias na Tabela 1 indicam que as durações de vogais de mulheres do grupo IA L2 estão mais próximas do grupo IA L1 do mesmo sexo do que nos dois grupos de falantes masculinos.

Uma análise de regressão múltipla com fatores fixos foi realizada na linguagem de programação R (R CORE TEAM, 2012) para investigar como os grupos de idiomas (inglês americano como L1 ou L2), sexo (falantes masculinos ou femininos) e acento (durações de vogal total ou reduzida) afetam a duração da vogal em inglês americano como produzidas por falantes da língua 
como L1 e como L2 (ver Tabela 2).

Tabela 2 - Análise de regressão múltipla na duração por grupos de idiomas, tipo de vogal e sexo

\begin{tabular}{lcccc}
\hline & $\boldsymbol{B}$ & $\boldsymbol{S E}$ & $\boldsymbol{t}$ & $\boldsymbol{p}$ \\
\hline (Intercept) & -0.30 & .11 & -2.63 & .08 \\
Grupos de idiomas & 0.22 & .07 & 3.07 & .02 \\
Tipo de vogal & -1.16 & .16 & -7.23 & $<.01$ \\
Sexo & 0.43 & .07 & 6.02 & $<.01$ \\
Tipo de vogal*sexo & -0.06 & .10 & -0.58 & .57 \\
Grupos de idiomas*tipo de vogal & 0.22 & .10 & 2.16 & .03 \\
Grupos de idiomas*sexo & -0.10 & .05 & -2.28 & .02 \\
Grupos de idiomas*tipos de vogal*sexo & 0.01 & .06 & 0.17 & .87 \\
\hline
\end{tabular}

* significância estatística, se $\mathrm{p}<.05$

Observamos os principais efeitos dos fatores "grupos de idiomas", "sexo" e "tipo de vogal", bem como interações significativas entre "grupos de idiomas" e "sexo", e "grupos de idiomas" e "tipo de vogal". Estes resultados apoiam as conclusões extraídas da tabela 1: o efeito principal significativo da quantidade da vogal indica que as vogais plenas e reduzidas em inglês diferem na duração. A duração das vogais em geral também foi claramente diferente nos dois grupos de linguagem, sendo mais longo no grupo L2 do que no grupo L1 - devido ao fato de que as durações de L2 para vogais não acentuadas eram muito longas em relação à norma L1.

A interação observada entre o tipo de vogal e o grupo de idiomas indica que as diferenças globais na produção de vogais plenas e reduzidas são dependentes de se as vogais inglesas foram produzidas por americanos ou brasileiros. Além disso, ambos os homens e mulheres mostraram diferenças significativas na duração da vogal inglesa dependendo de se eram falantes de IA L1 ou IA L2 ingleses (como encontrado na interação entre o grupo de idiomas e o tipo de vogal).

Os resultados indicam que as vogais plenas e as vogais reduzidas são produzidas distintamente dependendo do sexo e do grupo da língua. Para descobrir se brasileiros e americanos mostraram uma redução de duração semelhante às vogais inglesas, um olhar mais atento é necessário às durações de vogais reduzidas. As vogais reduzidas presentes neste conjunto de dados são a vogal central (também conhecida como schwa, símbolo fonético /ə/) e a segunda vogal mais reduzida da língua, meio-alta meio-frontal (símbolo fonético /I/), que foram produzidas tanto na primeira como na segunda sílabas das palavras trissilábicas. Entre todas, 5.673 vogais 
reduzidas estavam disponíveis em nosso conjunto de dados. Após a exclusão dos outliers, um total de 5.535 itens permaneceram para análise.

A análise estatística mostrou que as vogais de schwa são produzidas globalmente com durações mais longas do que vogais meio-frontal meio-alta. Isto é devido às características intrínsecas de vogais fechadas e abertas (Klatt, 1976). As vogais médias, como Schwas, necessitam de maior tempo de articulação devido à abertura da mandíbula do que as vogais altas, como vogais meio-alta meio-frontal.

Homens e mulheres de ambos os grupos de idiomas produzem diferenças comparáveis em durações de vogais, que são relativamente maiores nas produções brasileiras do que nas americanas. Os falantes de IA masculinos produziram vogais mais curtas do que falantes IA femininos em grupos de L1 e de L2. Para testar se as diferenças entre a redução vocálica dos brasileiros e americanos são significativamente diferentes, fizemos duas análises de regressão múltipla, uma para vogais meio-frontal meio-alta e outra para vogais de schwa, tomando como variável dependente a "duração vocálica" e como variáveis independentes "Grupo de Idiomas" (inglês americano como L1 ou L2) e "sexo". No total, foram produzidos 3.600 Schwas. Depois que os outliers foram excluídos, um total de 3.474 tokens permaneceram para a análise estatística. Uma análise de regressão múltipla com “Grupo de Idiomas" e "sexo" como variáveis dependentes mostraram que o grupo de idiomas é significativo $(\beta=0,35, \mathrm{SE}=0,8, p<.001)$, e o Sexo é significativo $(\beta=0,23, \mathrm{SE}=0,8, p=.04)$ como fatores principais, mas insignificante na interação $(p$ $>$.05).

A produção de vogal meio-frontal meio-alta totalizou 2.073 tokens, mas após a exclusão dos outliers, 2.040 tokens permaneceram para análise estatística. Os resultados da análise de regressão múltipla mostraram o mesmo padrão que na análise de schwa, o grupo de idiomas e o sexo são significativos como principais fatores ( $(\beta$ “Grupo de Idiomas" $=0.29, \mathrm{SE}=0,8, \mathrm{p}<.001)$ e $\left.\left(\beta^{\prime \prime} \operatorname{Sexo}^{\prime \prime}=0,31, \mathrm{SE}=0,8, p<.001\right)\right)$, mas eles não são significativos em interação $(p>$ > 05). Como nenhuma interação significativa entre o grupo de idiomas e o sexo foi encontrada, os resultados indicam que os efeitos do grupo de idiomas e sexo na duração da vogal são independentes uns dos outros.

\section{Considerações finais}

Seguindo estudos que investigam diferenças de duração de vogais específicas do sexo, os 
resultados deste estudo indicam que as mulheres produziram vogais mais longas do que os homens ao falarem em sua L1, neste caso, IA. Este padrão também foi encontrado nas produções de no grupo de falantes de IA como L2, o que não havia sido reportado na literatura antes de XXX (2019).

Nossos resultados estatísticos não mostraram nenhuma dependência entre as variáveis "grupo de idiomas" e "sexo", assim vogais longas produzidas por mulheres, é algo que ocorre independentemente da língua usada pelos falantes ou de dominância linguística (L1 ou L2). Portanto, há dois fatores independentes que motivam a produção mais longa por mulheres, que está ligado a especificidade do sexo; e outro fator que motiva as vogais serem produzidas com maior duração tanto por mulheres quanto por homens, que é um fator da aquisição de L2.

Por fim, investigamos a redução de vogais na produção de palavras por falantes monolíngues de inglês e falantes de inglês como L2. Confirmando a nossa hipótese, os falantes nativos de inglês reduziram a duração das vogais em posição não acentuada em maior extensão do que os falantes não-nativos. Essa descoberta sugere que os bilíngues têm um sistema misto de L1 e L2 responsável por realizações fonéticas não nativas. Segundo nossos resultados, se fossemos responder com um "sim" ou com um "não" à nossa pergunta do título deste artigo "Adquirindo as durações vocálicas de L2, ou não?" a resposta objetiva, porém superficial, teria que ser "não", pois ao menos superficialmente, os falantes de inglês como L2 não produzem as durações vocálicas tais como os falantes nativos. Contudo, as características fonéticas mescladas de L1-L2, como a duração vocálica dos falantes de IA (L2), podem ser "corrigidas" pelo contexto de interação, de modo que falantes nativos, embora percebam que a produção vocálica é não nativa, consigam decodifica-la como o fonema-alvo, e como consequência, ativar a palavra-alvo.. Resta analisar em futuros testes de percepção, se este é de fato o caso.

\section{Referências}

BAPTISTA, B. O. Adult phonetic learning of a second language vowel system. In B.Baptista and, M. Watkins (Eds.) English with a Latin Beat: Studies in Portuguese/Spanish - English, Interphonology (p. 19-40). Amsterdam: John Benjamins, 2006.

Bion R. A. H., Escudero, P., Rauber, A. S., \& Baptista, B. O. (2006). Category formation and the role of spectral quality in the perception and production of English front vowels. Proceedings of INTERSPEECH, Pittsburgh, p. 1363-1366, 2006.

BOERSMA, P.; WEENINK, D. Praat, a system for doing phonetics by computer. Glot International, 
5(9/10), 341-347, 2001.

CUTLER, A. Forbear is a homophone: Lexical prosody does not constrain lexical access. Language and Speech, 29, p. 201-220, 1986.

ERICSDOTTER, C.; ERICSSON, A. M. Sex differences in vowel duration in read Swedish: preliminary results. Working Papers, 49, 34-37, 2001.

ESCUDERO, P.; BOERSMA, P.; RAUBER, A.S.; BION, R.A.H. A cross-dialect acoustic description of vowels: Brazilian and European Portuguese. The Journal of the Acoustical Society of America 126 (3), 1379-1393, 2009.

ETS - Measuring the Power of Learning. ${ }^{\circledR}$ Copyright $(C 2015$ by Educational Testing Service.

HAAN, J.; VAN HEUVEN, V. J. Male vs. female pitch range in Dutch questions. In: Proceedings of the XIV International Conference of Phonetics Sciences (ICPhS), San Francisco, 1581-1584, 1999.

HAAS, A. Male and Female Spoken Language Differences: Stereotypes and Evidence. Psychological Bulletin, 86 (3), 615-626, 1979.

KLATT, D. H. Linguistic uses of segmental duration in English: Acoustic and perceptual evidence. Journal of the Acoustical Society of America, 59, 1208-1221, 1976.

LIBERMAN, M., \& PRINCE, A. On stress and linguistic rhythm. Linguistic Inquiry, 8, p. 249-336, 1977.

MAJOR, R. Stress and rhythm in Brazilian Portuguese. Language, 61, 259-282, 1985.

MARUSSO, A.; CRISTÓFARO-SILVA, T. A Contrastive Analysis of Schwa in English and Portuguese. New Sounds 2007: Proceedings of the Fifth International Symposium on the Acquisition of Second Language Speech, p. 350-360, 2007.

MEARA, P.; MILTON, J. (2006). X-Lex: the Swansea Vocabulary Levels Test. In Coombe, C., Davidson, P., and Lloyd D. (Eds.) Proceedings of the 7th and 8th Current Trends in English Language testing (CTELT) Conference TESOL, Arabia, UAE, 4, 29-39.

NOBRE, M. A.; INGEMANN, F. Oral vowel reduction in Brazilian Portuguese. In R. Channon \& L. Shockey (eds.). In Honour of Ilse Lehiste (pp. 195-206). Dordrecht, Foris Publications, 1987.

NOBRE-OLIVEIRA, D. The effects of training on the learning of American English vowels by native Brazilian Portuguese speakers. [Tese de Doutorado], Universidade Federal de Santa Catarina, Florianópolis, SC, Brasil, 2007.

PETERSON G. E.; LEHISTE, I. Duration of Syllable Nuclei in English. Journal of the Acoustical Society of America, 32, 693, 1960. 
POST DA SILVEIRA, Word stress in second language word recognition and production. Enschede: Ipskamp, 2016.

POST DA SILVEIRA, A.; VARKEVISSER, J. Sex differences in vocalic duration production in L1 and in L2. In Sasha Calhoun, Paola Escudero, Marija Tabain \& Paul Warren (eds.) Proceedings of the 19th International Congress of Phonetic Sciences, Melbourne, Australia 2019.

R CORE TEAM. R: A Language and Environment for Statistical Computing. $R$ Foundation for Statistical Computing, Vienna, Austria, 2012. http://www.R-project.org/

RAUBER, AS. Perception and production of English vowels by Brazilian EFL speakers. [Tese de Doutorado], UFSC, Florianópolis, SC, Brasil, 2006.

SIMPSON, A. P.; ERICSDOTTER, C. Sex-specific duration differences in English and Swedish. In: Proceedings of the 15th International Congress of Phonetics Sciences, 1113-1116, 2003.

SIMPSON, A. P. Possible articulatory reasons for sex-specific differences in vowel duration. In: Proceedings of the 6th International Seminar on Speech Production, Sydney, Australia, 2003.

SIMPSON, A. P. Phonetische Datenbanken des Deutschen in der empirischen Sprachforschung und der phonologischen Theoriebildung. Arbeitsberichte des Instituts fur Phonetik und digitale Sprachverarbeitung der Universität Kiel AIPUK , p.33, 1998.

SIMPSON, A. P. Phonetic differences between male and female speech. Language and Linguistics Compass, 3 (2), 621-640, 2009. 